\title{
Effects of Sustained Isometric Handgrip on Ventricular Systolic Time Intervals in Patients with Ischemic Heart Disease
}

\section{Inotropic State of the Left Ventricle during Treatment with Perhexiline Maleate and with Propranolol}

\author{
Salvatore Caponnetto, M.D., Mario Iannetti, M.D., \\ Carlo Pastorini, M.D., Maria Augusta Masperone, M.D., \\ Paola Perugini, M.D., and Giovannangelo Oriani, M.D.*
}

\section{SUMMARY}

It was found from our previous studies that patients suffering from ischemic heart diseasc with angina, showed either one of the patterns of the left ventricular systolic time intervals on isometric handgrip exercise.

Patients in class I or II NYHA showed a shortened pre-ejection period corrected for heart rate (PEPI), and a prolonged ejection period corrected for heart rate (LVETI) together with a decrease of the PEP/ LVET ratio. This response is normal, because it has also been found in normal subjects.

The patients in class III or IV NYHA showed a prolongation of PEPI, shortening of LVETI and an increase of the PEP/LVET ratio. This response is abnormal, because it occurs in patients with impaired cardiac performance and in ischemic ones with widespread asynergic areas.

Our aim here is to study the response of these 2 groups of patients treated for a 4-week period with perhexiline maleate. This new drug is chiefly used as anti-anginal drug, though it also has anti-arrhythmic properties.

The results show that the response of the left ventricle to isometric handgrip exercise in class I or II patients following perhexiline maleate treatment, is almost normal, thus confirming that the drug has no side effects on the cardiodynamics checked by the left ventricular systolic time intervals.

The responses of class III or IV patients after perhexiline maleate become normal. This shows that the drug acts by removing the contractile dysfunction. It can reasonably be assumed that this takes place following the elimination of the ischemia induced dyssynergic areas.

From the Section of Cardiology, Department of Internal Medicine, University of Genoa, Viale Benedetto XV N. 6, 16132 Genoa, Italy.

* Mcdical Director of Richardson-Merrel S.p.A. Naples.

Received for publication October 12, 1976. 
The effect of this drug has also been evaluated from a clinical point of view. A marked decrease in the frequency of anginal crises and the consequential reduction in the consumption of trinitroglycerin pills during perhexiline maleate treatment could thus be observed.

\section{Additional Indexing Words:}

Angina Triple product Polygraphic tracing Isometric exercise Left ventricular function Beta-blocking agent

$\mathrm{M}$

YOCARDIAL ischemia causes asynergic areas in the ventricular wall responsible for the various degrees of impaired contractility. $\left.\left.{ }^{6}, 23\right), 26\right), 34$ )

Any physical stress, such as the isometric handgrip exercise, can produce or enhance impaired contractility. ${ }^{51,21), 291,32), 48), 49)}$

Signs of left ventricular failure are the following: A) increase of enddiastolic pressure, B) decrease of $\mathrm{dP} / \mathrm{dt}, \mathrm{C}$ ) decrease of $\mathrm{Vmax}, \mathrm{D}$ ) decrease of the ejection fraction as well as lengthening of the pre-ejection time (LVET), and $E$ ) increase of the ratio of the 2 systolic times (PEP/LVET). 4), 15), 18), 20), $22), 25), 35), 36), 41), 55$ \}

In previous studies, ${ }^{50}$ ) we have demonstrated how different patients suffering from ischemic heart disease with angina, show 2 behavior patterns of left ventricular systolic time intervals after handgrip exercise.

Some of them, classified as Ist and IInd class NYHA patients, show a shortening of the pre-ejection period corrected with heart rate (PEPI) and a decrease of the PEP/LVET ratio. These are the reactions which can be observed in normal subjects and may be considered as hemodynamic responses to this exercise. ${ }^{33), 451}$

Other patients, belonging to the IIIrd and IVth class NYHA show a lengthening of the PEPI, a shortening of the LVET and increase of the PEP/LVET ratio. We have already seen this behavior in impaired contractility of the left ventricle. ${ }^{2), 16), 46)}$

The purpose of this paper is to establish whether the 4-week treatment with perhexiline maleate modifies the response in those patients suffering from ischemic heart disease with angina, who respond to the handgrip exercise with either type of behavior in the left ventricular systolic time intervals.

Perhexiline maleate is a new drug which is essentially an antianginal agent. ${ }^{8 /-11), 31), 37), 43)}$ It also has, however, antiarrhythmic properties. ${ }^{13), 53), 54)}$ The mechanism of action has not yet been established. However, although it is not a cardioselective beta-blocking agent, it has a similar favorable effect. 


\section{Method}

We studied 20 patients with ischemic heart disease 14 males and 6 females, ages ranging from 46 to 82 ). During the experiment it became necessary to discard 3 subjects. In 2 of them perhexiline maleate caused dizziness. The other one, who had already been suffering from repeated attacks of angina, died 6 days after taking the drug, with acute myocardial infarction. However, we do not believe that any responsibility for this can be attributed to the use of the drug. Therefore, our results were based on 17 patients.

Before starting the experiment the patients were submitted to a 1-week washout period, during which only trinitroglycerin (TNG) was permitted for the treatment of anginal attacks. After this period a polygraphic tracing was recorded on patients both at rest and at conclusion of a $3 \mathrm{~min}$ period of isometric handgrip exercise, performed at tension levels of $30 \%$ and $50 \%$ of the maximum voluntary contraction. Each patient was instructed to avoid a Valsalva maneuver during the handgrip exercise. In some cases it was not possible to obtain $50 \%$ of the maximal contraction owing to the onset of either angina or muscular exhaustion. PEPI and LVETI and the PEP/LVET ratio ${ }^{56-58)}$ were calculated from the recorded polygraphic tracing. These calculations were derived from measurements of 5 consecutive cardiac cycles and the average of the data obtained was then considered. In this way it was possible to determine the behavior curve relative to the handgrip exercise of each patient. By multiplying the heart rate by the arterial systolic pressure and the total ejection time (so called triple product), we obtained indications concerning the myocardial oxygen consumption behavior. $14), 17), 28), 51$ )

Every day each patient was given $300-400 \mathrm{mg}$ doses of perhexiline maleate or $120 \mathrm{mg}$ of propranolol. A cross-over comparison amongst patients was made as an experimental test. The period of drug treatment for each patient was 4 weeks, and the patients for each drug were selected at random. A 2-week wash-out period with placebo was interpolated between the 2 active treatments. Conditions of "single blindness" were maintained between placebo and perhexiline since the tablets were undistinguishable in form from the original ones. Conditions of "single blindness" did not hold for propranolol since the obvious effects of bradycardia could easily be detected even by the patient himself.

The polygraphic tracing during handgrip exercise was recorded at the end of the 4-week period of treatment with the 1st drug, at the end of the following 2-week period of wash-out with placebo and again at the end of the 4-week period of treatment with the 2 nd drug. Thus the data of PEPI, LVET, and the PEP/LVET ratio were obtained during $30 \%$ and $50 \%$ handgrip exercise at the end of the various periods of treatment. As far as the polygraphic tracing data were concerned, a cross-over analysis of variance was performed only for the changes relative to the $30 \%$ handgrip exercise, since complete data with balanced sequences were available only for this parameter. With this test we noticed that the changes in the polygraphic data were not affected by the period effect. Consequently, the following tests on the $50 \%$ exercise with patients subdivided into groups according to NYHA criteria, were performed by a paired student's t-test, with comparison of active drugs versus base placebo. 
A cross-over variance test was performed in order to have a statistical evaluation of the number of angina crises and the patient's consumption of TNG pills. We used the differences' method reported by Li. ${ }^{30}$ The variable considered was the number of attacks and pills in the last 2 weeks of active treatment as reported by Amstrong et al. ${ }^{1)}$ This was in order to avoid the influence of carry over effects and to choose a period in which perhexiline maleate consumption could reach a constant drug metabolic condition of equilibrium.

It must be pointed out that the data concerning the attacks and the pill consumption were submitted to metemetric transformation $\left(x^{\prime}=x+0.5\right)$ in order to stabilize the variance.

\section{RESULTS}

The data relative to the triple product, that is, the heart rate multiplied by arterial systolic pressure and total ventricular ejection time are summarized in Fig. 1. It can be seen how the triple product increases with the degree of handgrip exercise. The rise of the value is only slight in moments of stress at the end of the period of treatment with propranolol, but on the average it becomes less noticeable at the end of the period of treatment with perhexiline maleate.

However, because of the high degree of individual variability and the limited number of cases tested, the cross-over variance concerning the data of the triple product changes after a $30 \%$ handgrip exercise, did not show a significant difference between perhexiline maleate and propranolol.

The same analysis excludes the possible period effect on the drug's action.

Since we did not have enough patients to submit to $50 \%$ isometric stress, we could only perform a paired student's t-test for data between perhexiline maleate and propranolol. Even here the rise of the triple product under stress was, on average, lower with perhexiline although it was still not significant.

The behavior of PEPI in Ist and IInd class and IIIrd and IVth class NYHA patients is shown in Fig. 2 respectively as groups a and b. It can be seen from group a that PEPI decreased during stress provoked by the isometric handgrip exercise when patients were treated both with placebo and perhexiline maleate as well as with propranolol. From group b it can be seen that during isometric exercise PEPI increased when the patients were treated with placebo and propranolol, while it decreased with perhexiline maleate.

Statistics show that the changes during perhexiline maleate treatment are highly significant $(\mathrm{p}<0.01)$ compared with the placebo treatment. Between the latter and propranolol there is a lower level of significance $(p<0.1)$.

In the cross-over variance based on the data taken from all the patients, with regard to the changes of PEPI after a $30 \%$ stress, the difference between 


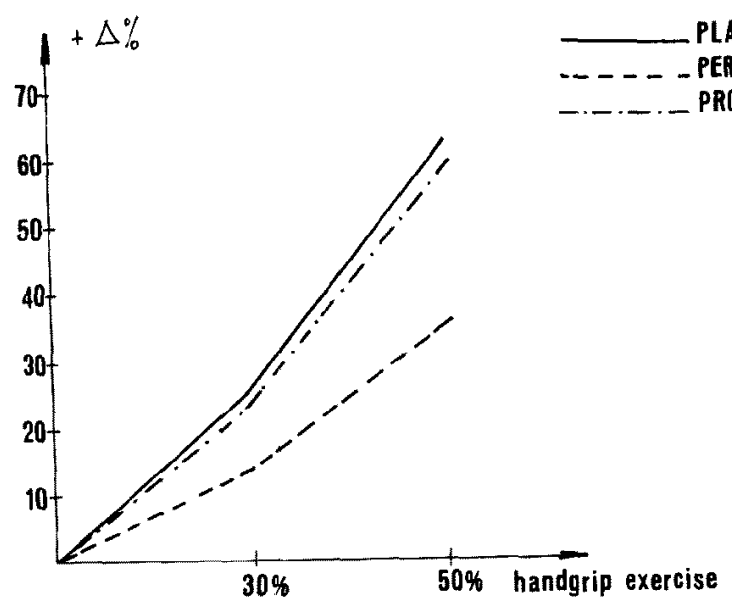

Fig. 1. Behavior of triple product in all patients checked. On the ordinate, run the percentage variations concerning the base values, and on the abscissa, the levels of isometric exercise.
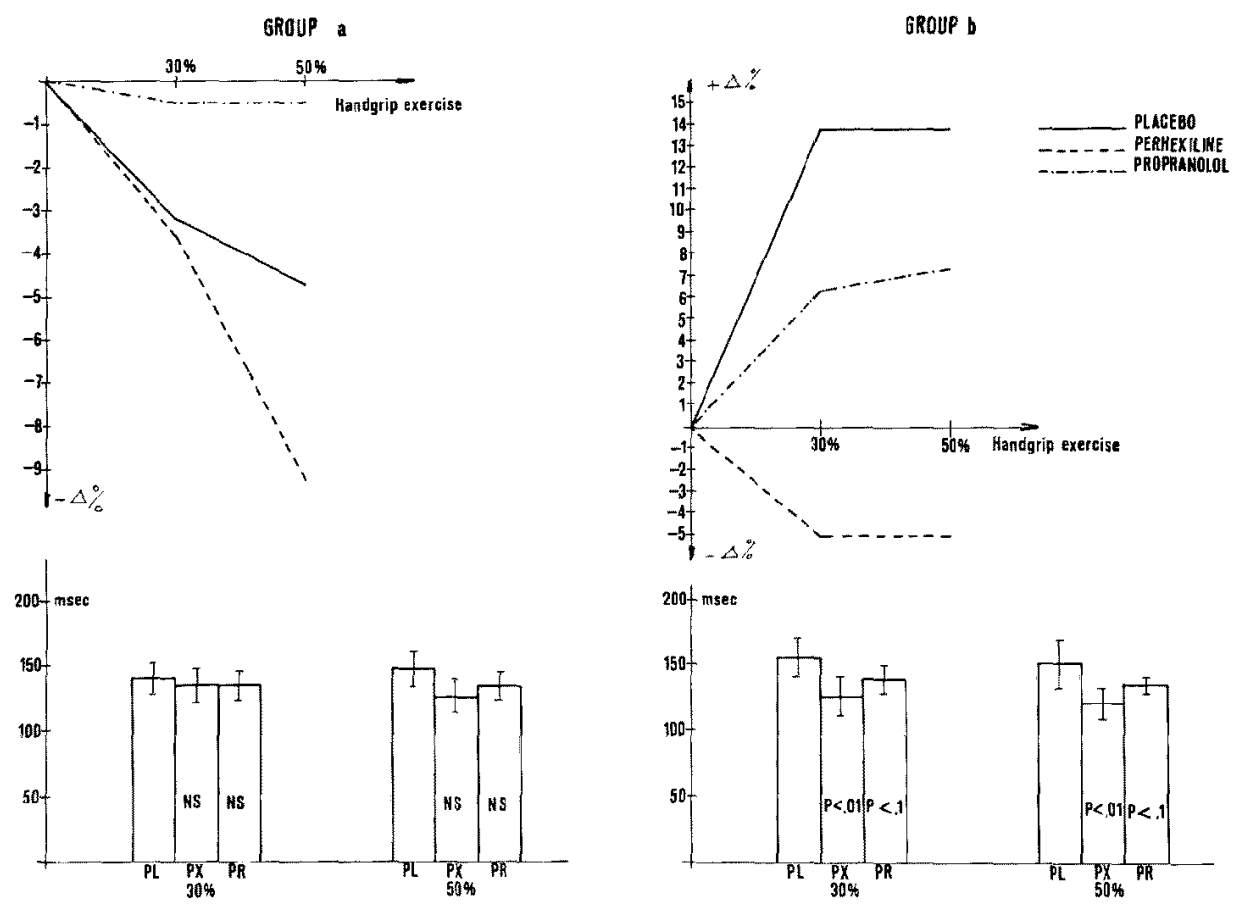

Fig. 2. Behavior of PEPI in ischemic patients. Above the percentage variations in reference to base values for each level of the handgrip exercise. Below the average values found in patients with the standard deviations and relationship between drugs and placebo. Group a: I and II NYHA class patients; Group b: III and IV NYHA class patients. 
perhexiline maleate and propranolol is statistically significant. In fact, while perhexiline maleate under stress gives an average decrease of $7.06 \mathrm{msec}$, propranolol gives a PEPI increase of $5.93 \mathrm{msec}$.

The behavior of LVETI is shown in Fig. 3. It can be seen from group a that in Ist and IInd class NYHA patients there is a relationship between LVETI and the degree of stress. This increase could be noticed even when the patients were treated with perhexiline maleate and propranolol.

The statistics do not give evidence of any significant change between the 2 drugs on one side and the placebo on the other.

It can be seen from group b that in IIIrd and IVth class NYHA patients, LVET undergoes some changes. The handgrip exercise, after placebo treatment, gives a decrease of this index. When the same exercise follows a perhexiline or propranolol treatment an increase of LVETI can be observed.

The changes caused by the drugs compared to those caused by the placebo are highly significant both during $30 \%$ and $50 \%$ stress $(p<0.02)$. The cross-over variance carried out on data concerning the changes under
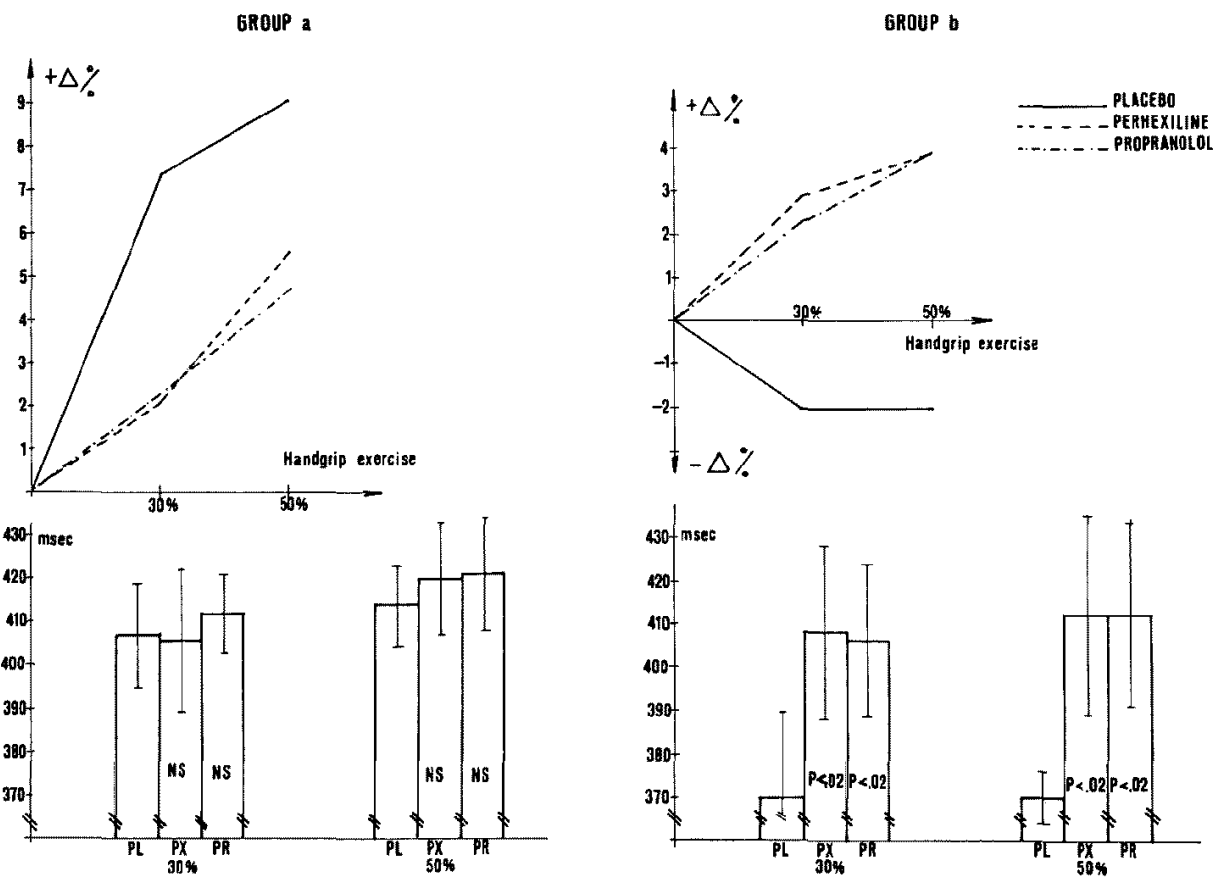

Fig. 3. Behavior of VLETI in isochemic patients. Above percentage variations in reference to base values for each level of the handgrip exercise. Below the averages of the values found in the patients with standard deviations and relationship between drugs and placebo. Group a: I and II NYHA class patients; Group b: III and IV NYHA class patients. 
$30 \%$ stress did not show any significant difference between the 2 active drugs on the LVETI.

The behavior of the ratio PEP/LVET during handgrip exercise carried out by ischemic patients is shown in Fig. 4. In group a the curve refers to Ist and IInd class patients. During stress the index, both in patients treated with placebo and in those treated with perhexiline maleate and propranolol becomes smaller. There is no significant change in the behavior between the 2 drugs and the placebo.

In group b the ratio PEP/LVET refers to IIIrd and IV th class patients. It is clear how handgrip exercise following placebo increases this ratio, whereas it causes it to decrease after perhexiline maleate treatment.

The changes caused by perhexiline maleate compared to those caused by the placebo are statistically significant both with $30 \%(\mathrm{p}<0.01)$ and $50 \%$ $(p<0.05)$ stress. Whether the patients were treated with propranolol or with placebo the results were the same, but statistically there is a slight difference $(\mathrm{p}<0.05$ with $30 \%$ and $50 \%$ ).
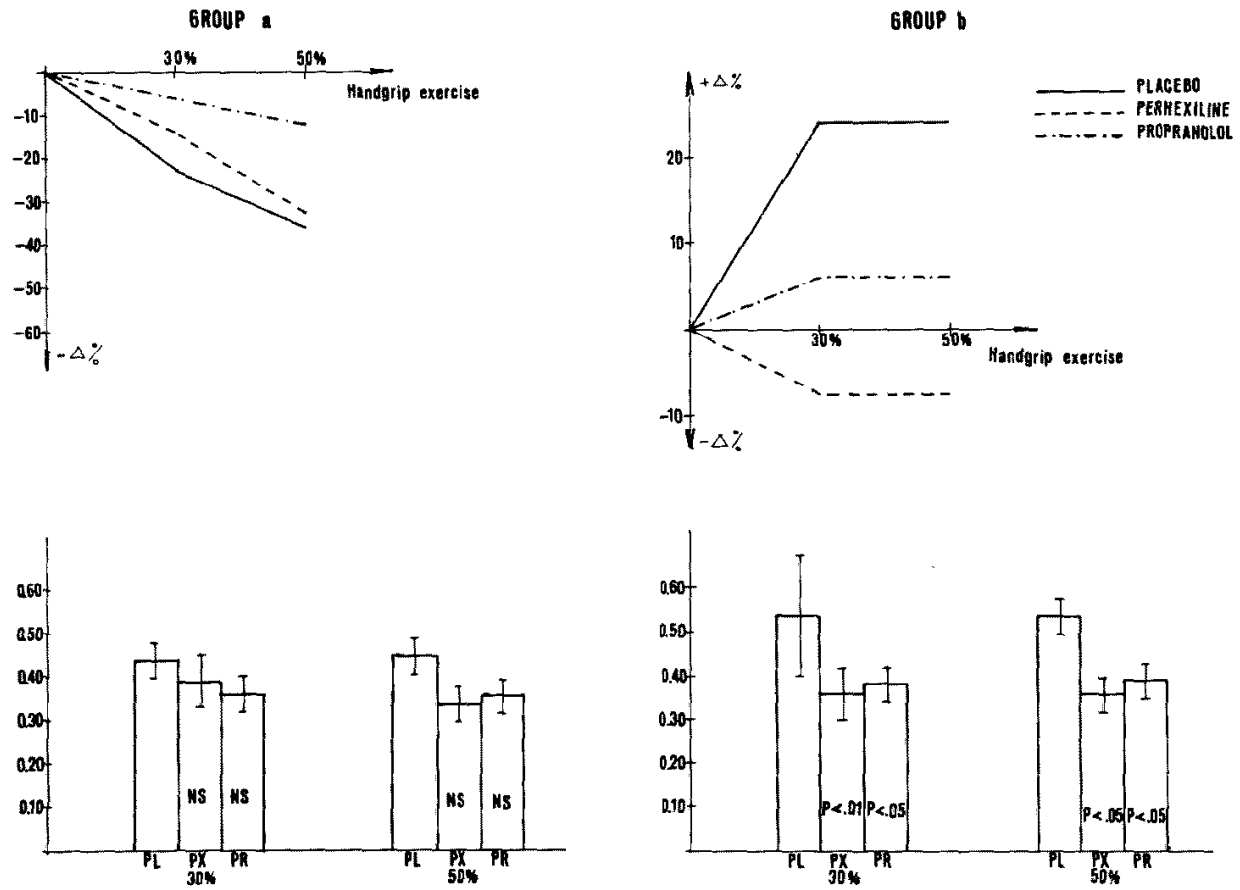

Fig. 4. Behavior of the PEP/LVET ratio in ischemic patients. Above percentage variations in reference to base values for each level of the handgrip exercise. Below the averages of the values found in each patient with standard deviations and relationship between drugs and placebo. Group a: I and II NYHA class patients; Group b: III and IV NYHA class patients. 


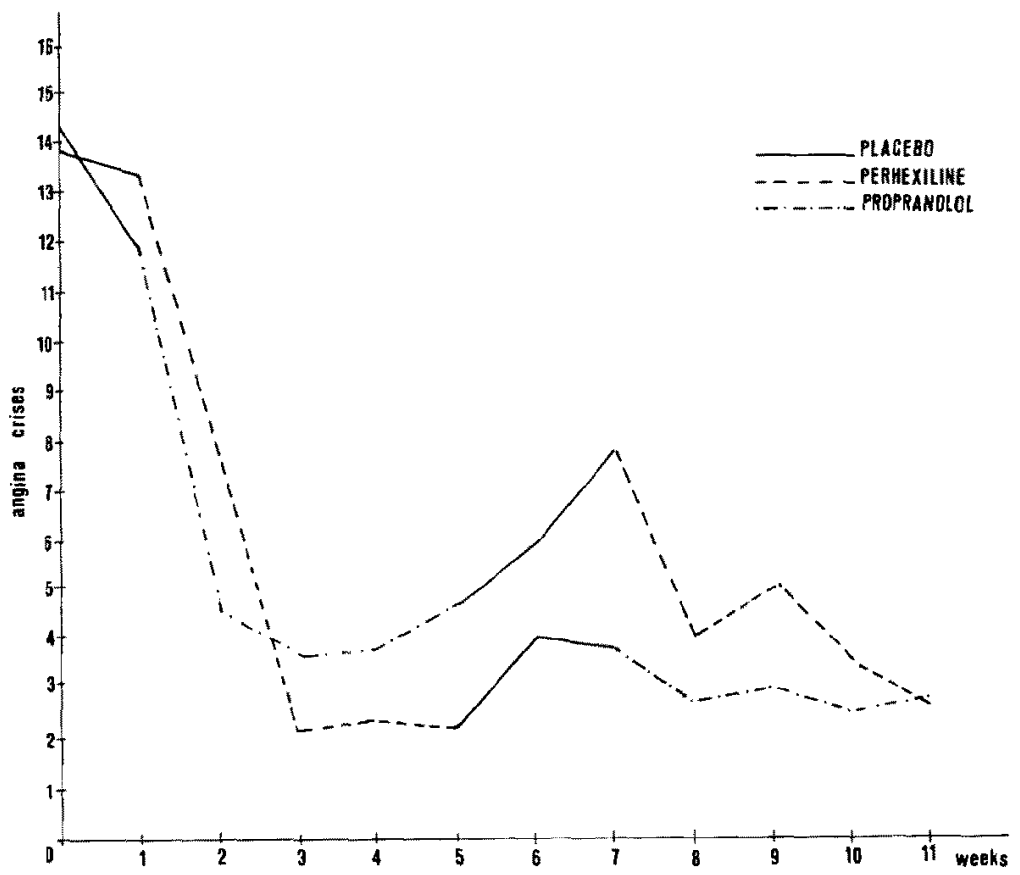

Fig. 5. Number of angina crises compared to placebo.

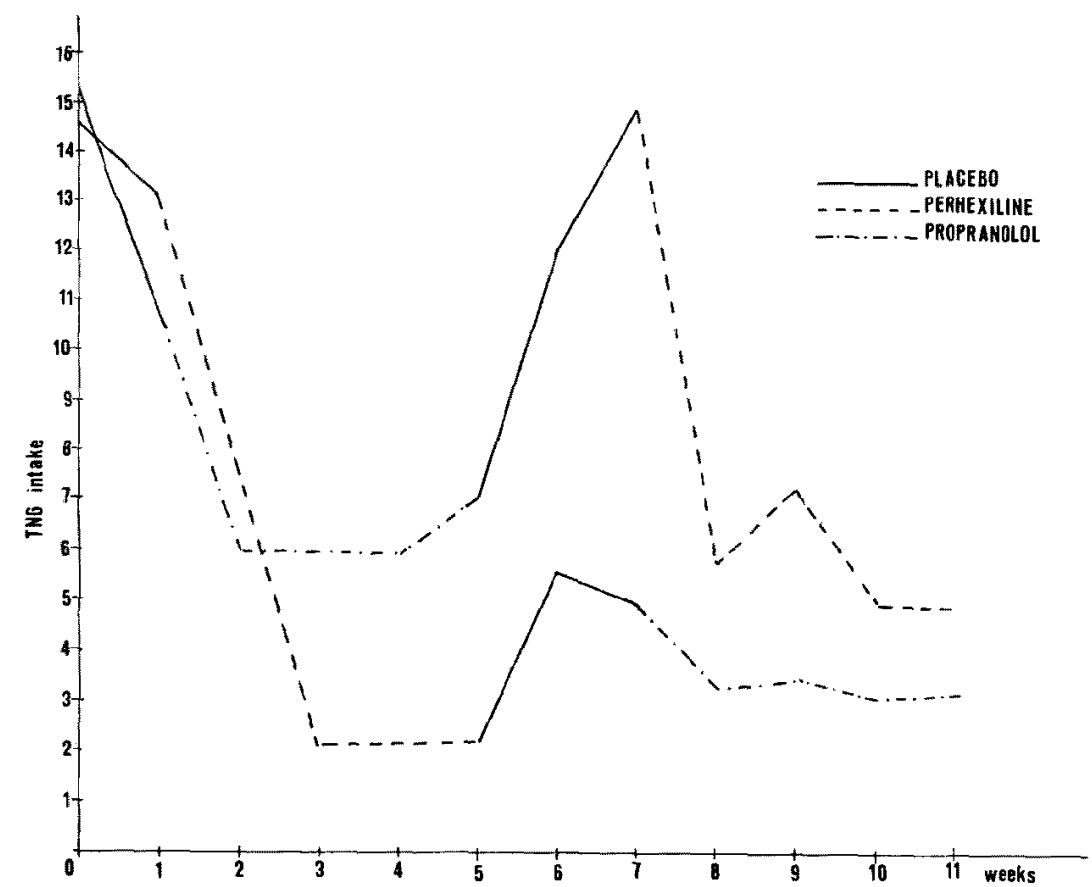

Fig. 6. Intake of TNG pills compared to placebo. 
The variability analysis was carried out in the same way for PEPI and LVETI. It showed a statistically significant difference for the PEP/LVET ratio, between perhexiline maleate (average ratio variability $=0.03$ ) and propranolol (average ratio variability $=0.01$ ).

In Figs. 5 and 6 the clinical effects of perhexiline maleate and propranolol are shown in relation to the number of angina crises (Fig. 5) and TNG pills taken by the patients (Fig. 6). Both active drugs decrease the number of angina crises and TNG consumption by $65-75 \%$ compared to the values obtained with placebo.

The variability analysis performed in accordance with a cross-over did not show significant differences with regard to the frequency of attacks and pill consumption in the second 2 weeks between the 2 active treatments.

However, as can be seen from the figures, we had a marked clinical improvement with propranolol, 3-4 days following treatment, but it disappears just as markedly when the drug is withdrawn.

With perhexiline maleate the 65-75\% decrease of angina crises and TNG pill intake is obtained on the other hand only after 6-10 days, and the effects wear off just as slowly when the drug is withdrawn.

\section{Discussion}

The results lead us to make some interesting findings. First of all the increase of the triple product during handgrip exercise is established. ${ }^{14), 28,48)}$ This is indicative of higher myocardial oxygen consumption. ${ }^{23}$ It has been demonstrated that the handgrip exercise can emphasize the degree of failure of left ventricular performance in patients with different types of cardiopathy. ${ }^{183,19)}$ This happens particularly in those with ischemic heart diseases when neither the ST segment displacement, nor angina symptoms ${ }^{13), 29)}$ are taken as evaluation criteria of the stress response, but rather as indices of myocardial contractility. ${ }^{2), 20), 38), 52)}$ In patients performing a stress at the end of perhexiline treatment, the oxygen consumption increase is lower than in those observed both after placebo and after propranolol. Although from a statistical point of view these data need to be verified on a larger number of patients, they appear to be worthy of note.

This behavior during treatment with perhexiline maleate is similar to that observed with other antianginal drugs which act through a metabolic type action. It has not yet been demonstrated whether this effect is obtained directly with the perhexiline maleate just as would be with any beta-blocking drug, or indirectly by the peripheral effects which it seems to produce. The latter supposition seems to be the most probable one, ${ }^{24), 39), 44}$ and for this reason, 
today perhexiline maleate is considered an anti-anginal drug which has the same effects as a beta-blocking agent although it is not included in this category. ${ }^{101,31,43 \text { ) }}$

As far as the behavior of the left ventricular systolic time intervals is concerned, the 2 types of results depending upon grade of the ischemic disease, were confirmed.50) In the Ist and IInd class patients the handgrip exercise produces: decrease of PEPI, increase of LVETI and decrease of the ratio $\mathrm{PEP} / \mathrm{LVET}$. This response is normal since it is also observed in patients with no cardiovascular disorders. The responses to handgrip exercise in the same patient after perhexiline maleate and propranolol intake are not different from the normal responses mentioned above. This proves that perhexiline maleate has no negative effect on the cardiodynamics of those patients checked by means of the left ventricular systolic time intervals, at least when they are treated with the doses used during the observation period.

In the IIIrd and IVth class patients, isometric stress leads to a lengthening of PEPI, a shortening of LVETI and an increase of the ratio PEP/LVET. This response is abnormal. It can in fact be observed in patients with heart failure ${ }^{3,401}$ and in ischemic cardiopathy with wide asynergic areas. ${ }^{61,7), 12,271}$ Responses to handgrip exercise carried out on the same patients after perhexiline maleate are normal. This consequently proves that perhexiline maleate acts by removing the contractile cardiac dysfunction and this probably takes place because of the elimination of asynergic areas caused by ischemia.

In studying the effects of perhexiline maleate on the number of angina crises and TNG pill consumption, we confirmed its properties as an antianginal drug, and from the conclusions we reached we have the impression that it acts through a cardiovascular mechanism.

In conclusion, it seems likely that perhexiline maleate decreases myocardial oxygen consumption. It normalizes the left ventricular systolic time intervals when they are abnormal, but does not change them when they are normal. Finally it decreases the number of angina crises and TNG pill consumption.

\section{REFERENCES}

1. Amstrong ML: A comparative study of perhexiline, beta-adrenergic blocking agents and placebos in the management of angina pectoris. Postgrad Med J 49 (suppl 3): 108, 1973

2. Aronow WS, Bowyer AF, Kaplan MA: External isovolumic contraction times and left ventricular ejection time ratios at rest and after exercise in coronary heart disease. Circulation 43: 59,1971

3. Benchimol A, Dimond EG, Shen Y: Ejection time in aortic stenosis and mitral stenosis. Am J Cardiol 5: 728, 1960

4. Caponnetto S, Martini U, Iannetti M, Pastorini C: Effetti del lavoro muscolare sui tempi 
della rivoluzione cardiaca in soggetti normali ed in alcune situazioni patologiche. Arch Maragliano 22 (suppl 1): 1966

5. Chaitman BR, Briton JD, Rahimtoola SH: Left ventricular wall motion assessed by using fixed external reference systems. Circulation 48: 1043, 1973

6. Chatterjee K, Sacoor M, Sutton GC, Miller GA: Angiographic assessment of left ventricular function in patients with ischemic heart disease without clinical heart failure. Brit Heart $J$ 33: 559,1971

7. Chatterjee K, Swan HJC, Parmeey WW, Sustaita H, Marcus HS, Matloff J: Influence of direct myocardial revascularization on left ventricular asynergy and function in patients with coronary heart disease: with and without previous myocardial infarction. Circulation 42 : 276,1973

8. Cherchi A, Fonzo R, Bina M, Raffo M: Influence of perhexiline on the effort tolerance test in angina pectoris. Postgrad Med J 49 (supp. 3): 67, 1973

9. Corsini G, Correane E, Oriani GA, Persico S, Tritto C: Esperienza clinica con perexiline maleato nel trattamento dell'angina pectoris. Giorn Ital Cardiol 5: 73, 1975

10. Datey KK, Dalvi CP, Kelkar PN, Bhootra RK: Perhexiline maleate, a new anti-anginal drug evaluated by modified double blind double cross-over study. Angiology 25: 406, 1974

11. Dettori AG, Malagnino G, Fatti F, Oriani GA: Perhexiline versus prenylamine. A controlled clinical trial in coronary insufficiency. Postgrad Med J 49 (suppl 3): 113, 1973

12. Diamant B, Shapiro M, Fleming EJ, Killip T III: Direct and indirect assessment of left ventricular dysfunction in coronary artery disease. Am J Cardiol (abstr) 25: 92, 1970

13. Drake FT, Singer $\mathrm{DH}_{3}$ Haring C, Dirnberger G: Evaluation of anti-arrhythmic efficacy of perhexiline maleate in ambulatory patients by holter monitoring. Postgrad Med J 49 (suppl 3): 52,1973

14. Fisher ML, Nutter DO, Jacobs W, Schlant RC: Haemodynamic responses to isometric exercise (handgrip) in patients with heart disease. Brit Heart $J$ 35: 422, 1973

15. Frank MN, Heberen NU: The effects of handgrip and exercise on systolic time intervals in human subjects. Am Med Sc $261: 219$, 1971

16. Garrad CL Jr, Weissler AM, Dodge HT: The relationship of alteration in systolic time intervals to ejection fraction in patients with cardiac disease. Circulation 42: 455, 1970

17. Grossman W, McLaurin LP, Saltz SB, Paraskos JA, Dalen JE, Dexter L: Changes in the inotropic states of the left ventricle during isometric exercise. Brit Heart J 35: 697, 1973

18. Haessly JC, Messin R, Desgre S, Vandermonten P, Demaret B, Denolin H: Comparative response to isometric (static) and dynamic exercise tests in coronary disease. Am J Cardiol 33: 791,1974

19. Helfant RH, De Villa MA, Meister SG: Effect of sustained isometric handgrip exercise on left ventricular performance. Circulation 44: 982,1971

20. Helfant RH, Banka VS, De Villa MA, Pine R, Kabde V, Meister S: Use of bicycle ergometry and sustained handgrip exercise in the diagnosis of presence and extent of coronary heart disease. Brit Heart J 35: 1321, 1973

21. Herman MV, Heinde RA, Klein MD, Gorlin R: Localized disorders in myocardial contraction asynergy and its role in congestive heart failure. New Engl J Med 277: 222, 1967

22. Hodges M, Halpern BL, Friesinger GC, Dagenois GR: Left ventricular pre-ejection period and ejection time in patients with acute myocardial infarction. Circulation 45: 933, 1972

23. Hood WB, Covelli VH, Abelman WH, Normal JG: Persistence of contractile behavior in the acutely ischemic canine ventricle. Circulation 38: 102, 1968

24. Hudak WJ, Lewis RE, Lucas RW, Kuhn WL: Review of the cardiovascular pharmacology of perhexiline. Postgrad Med J 49 (suppl 3): 16, 1973

25. Iannetti M, Martini U, Caponnetto S: Comportamento di alcuni tempi costituenti la sistole ventricolare durante lavoro dosato in pazienti affetti da insufficienza cardiaca sottoposti a trattamento cardiocinetico. Minerva Medica 57 (43): 1991, 1966

26. Katz AM, Hecht HH: The early "pump" failure of the ischemic heart. Am J Med 47: 
497,1969

27. Khama PK, Shan PM, Kramer DH, Schaefer RA, Tager I: Effects of altered preload on left ventricular systolic time intervals in acute myocardial infarction. Brit Heart J 35: 1102, 1973

28. Krayenbuehl HP, Rutishauser W, Shoenbeck M, Amende I: Evaluation of left ventricular function from isovolumic pressure measurements during isometric exercise. Am J Cardiol 29: 323,1972

29. Kivowitz C, Parmley WW, Danoso R, Marcus H, Ganz W, Swan HGC: Effects of isometric exercise on cardiac performance. The grip test. Circulation 44: 994, 1971

30. Li CG: Introduction to Experimental Statistics. McGraw Hill, New York, 1964

31. Libretti A, Gregorini L, Valentini R, Concina B, Marini O, Masoni A, Antonioli G, Tomasi AM: Double-blind clinical trial with perhexiline in out-patients with angina pectoris. Postgrad Med J 49 (suppl 3): 105, 1973

32. Lowe DK, Rothbaum DA, McHenry PL, Corya BC, Knoebel SB: Myocardial blood flow response to isometric (handgrip) and tread mill exercise in coronary artery disease. Circulation 51 : 126, 1975

33. McConahay DR, Martin CM, Cheitlin MD: Resting and exercise systolic time intervals correlation with ventricular performance in patients with coronary artery disease. Circulation 45: 592,1972

34. Malmborg RO: A clinical and haemodynamic analysis of factors limiting the cardiac performance in patients with coronary artery disease. Acta Med Scand 177 (suppl): 426, 1965

35. Martin CE, Shaver JA, Thompson ME, Reddy PS, Leonard JJ : Direct correlation of external systolic time intervals with internal indices of left ventricular function in man. Circulation 44: 419,1971

36. Martini U, Iannetti M: Il comportamento di varie fasi del ciclo cardiaco durante il lavoro muscolare. Arch Maragliano 22: 147, 1966

37. Masoni A, Tomasi AM, Oriani GA: Clinical evaluation of perhexiline maleate in the treatment of patients with chronic coronary insufficiency. Am Heart J 90: 145, 1975

38. Metzger CC, Chough CB, Kroets FW, Leonard JJ: True isovolumic contraction time. Its correlation with two external indices of ventricular performance. Am J Cardiol 25: 435, 1970

39. Morledge J: Effects of perhexiline maleate in angina pectoris: a double-blind clinical evaluation with ECG-treadmill exercise testing. Postgrad Med J 49 (suppl 3): 64, 1973

40. Moskowitz RL, Weschler BM: Left ventricular ejection time in aortic and valve disease. Am J Cardiol 15: 809, 1965

41. Mullins CB, Leshin SJ, Mierzwiak DS, Matthewes OA, Blonquist $\mathrm{C}$ : Isometric exercise (handgrip) as a stress for evaluation of left ventricular functions. Circulation $\mathbf{4 1 - 4 2}$ (suppl 3): 122,1970

42. Pastorini C, Caponnetto S: Patognesi e fisiopatologia dell'ischemia miocardica. Rec Progr Med 57: 30, 1974

43. Pepine GJ, Schang SJ, Bemileer CR: Alteration of left ventricular responses to ischemia with oral perhexiline. Postgrad Med J 49 (suppl 3): 43, 1973

44. Pepine CJ, Schang SJ, Bemiller CR: Effects of perhexiline on coronary haemodynamic and myocardial metabolic responses to tachycardia. Circulation 48: 887, 1974

45. Pigott VM, Spodick DH, Rectra EH, Khan A: Cardiocirculatory responses to excrcise: physiological study by noninvasive techniques. Am Heart J 82: 632, 1971

46. Pouget JM, Willard SH, Bart RM, Naughton JP: Abnormal responses of the systolic time intervals to exercise in patients with angina pectoris. Circulation 43: 289, 1971

47. Quarry VM, Spodick DH: Cardiac responses to isometric exercisc. Comparative effcets with different postures and levels of exertion. Circulation 49: 905, 1974

48. Quinones MA, Gaasch WH, Waisser E, Thiel HG, Alexander JK: An analysis of the left ventricular response to isometric exercise. Am Heart J 88: 29, 1974 
49. Rahimtoola SH, Gau GT, Raphael MG: Cardiac performance after diagnostic coronary arteriography. Circulation 41: 537, 1970

50. Rosselli P, Martini U, Caponnetto S, Iannetti M, Pastorini G, Masperone MA: Comportamento dei tempi della sistole ventricolare sinistra in pazienti con cardiopatia ischemica sottoposti ad esercizio isometrico. Giorn Ital Cardiol 5: 364, 1975

51. Sarnoff SJ, Braunwald E, Welch GH, Case RB, Stainsby WN, Macruz R: Haemodynamic determinants of oxygen consumption of the heart with special reference to the tension timeindex. Am J Physiol 192: 148, 1958

52. Siegal W, Gilbert CA, Nutter DO, Schlant RO, Hurst JW: Use of isometric handgrip for the indirect assessment of left ventricular isometric function in patients with coronary atherosclerotic heart disease. Am J Cardiol 30: 48, 1972

53. Sukerman M: Clinical evaluation of perhexiline maleate in the treatment of chronic cardiac arrhythmias of patients with coronary heart disease. Postgrad Med J 49 (suppl 3): 46, 1973

54. Ten Eick RE, Singer DH: Effects of perhexiline on the electrophysiological activity of mammalian heart. Postgrad Med J 49 (suppl 3): 32, 1973

55. Vande W, Piessens J, Kesteloot H, De Gest H: A comparison of systolic time intervals derived from the central aortic pressure and from the external carotid pulse tracing. Circulation $\mathbf{5 1}$ : 310,1975

56. Weissler AM, Harris WS, Schoenfeld GD: Bedside techniques for the evaluation of ventricular function in man. Am J Cardiol 23:577, 1969

57. Weissler AM, Harris WS, Schoenfeld CD: Systolic time intervals in heart failure in man. Circulation 37: 149, 1968

58. Weissler AM, Peeler RG, Roehll WH: Relationships between left ventricular ejection time, stroke volume, and heart rate in normal individuals and patients with cardiovascular disease. Am Heart J 62: 367, 1961 